\title{
MODELIZAÇÃO: UMA POSSIBILIDADE DIDÁTICA NO ENSINO DE BIOLOGIA
}

\author{
Leandro Duso* \\ Luiz Clement** \\ Patricia Barbosa Pereira*** \\ José de Pinho Alves Filho***
}

RESUMO: A modelização possui um papel significativo para o ensino de ciências em geral. Porém, na Biologia, ainda é um tema pouco estudado. Neste artigo, identificamos o papel atribuído à modelização no ensino de ciências, particularmente no ensino de Biologia. Para tal, apresentamos a análise de uma atividade, desenvolvida em uma turma de segunda série do Ensino Médio, com o propósito de trabalhar a temática corpo bumano, mediante a construção de modelos representacionais. Com essa atividade, superamos a forma tradicional de apresentação do corpo humano nos livros didáticos, proporcionando aos estudantes uma compreensão abrangente sobre o que é e como ele está estruturado. Por fim, julgamos que a modelização é uma possibilidade efetiva para o processo de ensinoapredizagem na disciplina de Biologia.

Palavras-chave: Modelização. Ensino de Biologia. Ensino Médio.

\section{MODELIZATION: A DIDACTIC POSSIBILITY OF BIOLOGY TEACHING}

ABSTRACT: Modelization has a significant role in the teaching of science in general. However, there are few studies related to this topic. In this paper we will identify the role given to modelization in science teaching, particularly in biology teaching. To that end, we present an analysis of one activity, developed in a second grade class of high school, with the purpose to work the human body theme through the construction of representational models. With such activity we wish to overcome the traditional presentation of the human body in textbooks, providing students with a comprehensive understanding about what it is and how it is structured. Finally, we believe that modelization is an effective possibility for the teaching-learning process in biology.

Keywords: Modelization. Biology teaching. High school. 


\section{INTRODUÇÃO}

A história da Biologia como disciplina escolar se encontra marcada por dois períodos distintos. Na primeira metade do século XX, momento de sua consolidação curricular, era caracterizada por uma abordagem do ponto de vista propedêutico e elitista. Com o passar dos anos, essa visão passou a ser questionada foi substituída pela valorização da importância dos conhecimentos biológicos no campo de discussão da ciência e tecnologia, o que é próprio da sociedade contemporânea.

As modificações ocorridas ao longo do tempo não refletiram somente nos objetivos da disciplina, mas, principalmente, nos conteúdos a serem trabalhados e na estruturação curricular. Como aponta Krasilchik (2008), o exercício professoral de Biologia no Brasil variou muito entre as décadas de 1950 e 1990, sendo que, durante a primeira, algumas influências foram decisivas na estruturação dos materiais didáticos e modos de ser e fazer dos professores e estudantes em Biologia. Em um contexto no qual a maioria dos professores era composta por estrangeiros, as influências europeias foram relevantes. Além disso, a partir da década de 1950, com o desenvolvimento científico e tecnológico que teve como pano de fundo as disputas geradas pela Guerra Fria, os reflexos no campo curricular foram nítidos nas disciplinas científicas, com a criação e divulgação (em âmbito internacional) de grandes projetos de ensino que foram, inclusive, traduzidos em diversas línguas.

$\mathrm{Na}$ Biologia, bem como nas outras áreas do conhecimento científico, essas traduções vieram carregadas de inadequações, fragmentações e descontextualizações que exerceram grande influência na elaboração de materiais didáticos, sobretudo nos livros. A popularização do ensino de ciências, fenômeno da segunda metade do século XX, gerou um aumento da utilização dos livros didáticos no Brasil, vários deles isentos de análises e avaliações externas, o que também facilitou a divulgação de informações das mais diversas. Dentro dessa diversidade de informações, algumas parecem persistir nos livros, como "modelos de verdade" referentes ao conhecimento biológico.

Os livros didáticos de Biologia, em geral, contêm sua estrutura bem definida, o que contempla uma proposta metodológica. De acordo com Cicillini (1998), esses livros são divididos em grupos que incluem exemplares do tipo volume único ou coleção com três volumes (referentes aos três anos do Ensino Médio). Independente do grupo ao qual pertence, o livro geralmente apresentará figuras e esquemas que supostamente são disponibilizados para facilitar o aprendizado. Porém, acaba por simplificar a ciência de maneira exacerbada. Outra característica presente nesses materiais é o sequenciamento dos conteúdos, que pode ser interpretado pelos professores como o único possível. Essa organização, em geral, obedece a um critério de ordem de complexidade (é frequente, por exemplo, a organização dos conteúdos que vai dos estudos sobre célula aos estudos sobre organismo). Para Fracalanza (1993), o sequenciamento age também no apagamento do autor, pois o que se tem após várias edições é uma matriz neutralizada, em que o objetivo principal é o cumprimento dos exercícios do tipo "teste”. Essa é mais 
uma característica de destaque nos livros de Biologia do Ensino Médio, em que o vestibular se tornou o foco principal, favorecendo silenciamentos e repetições.

A simplificação resultante das características supracitadas, como a divisão em grupos, o sequenciamento e a presença de exercícios com enfoque no vestibular, tornam ainda mais explícitos os problemas relativos a alguns tópicos, como o corpo humano e os conceitos relacionados a ele. Nesse contexto, pensar o estudo do corpo humano é algo que requer outra consideração, já que os livros, em geral, desconsideram, nas figuras e esquemas apresentados, características como a heterogeneidade e a relação com outros textos, inclusive o do próprio livro didático. Assim, são continuamente presentes representações (figuras, em geral) de um corpo fatiado (facilitando o esquema), planificado, incompleto (em que se vê somente os sistemas, parte do todo), em geral masculino, sem pés, mãos e rosto. Além disso, esse corpo não se assemelha diretamente aos corpos dos que se dedicam a estudá-lo, pois as representações hegemônicas são destituídas de particularidades.

Dessa forma, pensar na possibilidade da modelização referente ao ensino de Biologia parece ser um caminho mais amplo, que vai contra a universalização, a fragmentação e a transmissão de um único modelo de verdade, tão presente nos textos (principalmente imagéticos) dos livros didáticos.

Diante disso, nos últimos anos, a modelização vem sendo apontada como uma alternativa educacional promissora para o ensino de ciências. Com ela, pretende-se ampliar a reflexão, o debate e a participação ativa dos estudantes no processo de sua aprendizagem. No entanto, no ensino de Biologia e de Química, a modelização ainda não alcançou o mesmo espaço que possui na Matemática e na Física. Acreditamos que isso se dá em decorrência da natureza conceitual dessas diferentes áreas do conhecimento, aliado à forma e ao tipo de modelos e processos de modelização que foram traduzidos para o contexto escolar. Os modelos aceitos e as teorias científicas da Física e da Matemática, em sua maioria, estão fortemente relacionados com a identificação de regularidades fenomenológicas, que resultam em descrições matemáticas. Já na Biologia e na Química, os modelos consensuados e as teorias, em geral, não possuem esta mesma característica, ou seja, as descrições matemáticas não são tão presentes.

A modelização chega à escola por meio das disciplinas de Matemática e de Física, e reflete a característica marcante dessas áreas de conhecimento. Assim sendo, parece ser fundamental que a modelização conduza a construção de um modelo passível de ser sintetizado em equações, ou seja, e descrições matemáticas.

No entanto, na Biologia, começam a surgir algumas iniciativas que visam ao desenvolvimento de atividades de modelização em sala de aula, baseadas na construção de modelos representacionais. Neste artigo, temos como objetivo identificar o papel atribuído à modelização no ensino de ciências, particularmente na Biologia, além de analisar um exemplo de atividade didático-pedagógica, desenvolvida em aulas de Biologia, que teve como propósito promover uma aprendizagem sobre o corpo humano, mediante a construção de modelos representacionais. 


\section{MODELOS E MODELIZAC̣ÃO NO ENSINO DE CIÊNCIAS}

Em termos gerais, a modelização retrata um processo de elaboração de modelos ou se refere à apropriação de modelos já elaborados e aceitados. Em função disso, a modelização abre espaço para análises, seja em relação à ciência, à Teoria de Modelos Mentais ou ao ensino de ciências, como processo de desenvolvimento de aprendizagem. Essas distintas análises em torno da modelização ganharam espaço nas agendas de pesquisa na área da educação científica e cada uma delas possui aspectos próprios, relacionados a determinados campos de conhecimento. A discussão em relação à ciência se caracteriza pela argumentação filosófica e epistemológica; a análise que envolve a Teoria de Modelos Mentais possui uma forte argumentação da linha cognitivista, e a análise da modelização no ensino de ciências enfatiza as teorias educacionais e pedagógicas.

Nos estudos feitos sobre modelos e modelização na educação em ciências, é importante destacar os trabalhos de Krapas et al (1997) e de Quinto \& Ferracioli (2008), pois ambos fazem uma reflexão sobre essa temática. Krapas et al (1997) se dedicaram a uma revisão de literatura de uma série de artigos publicados em periódicos de língua inglesa. A existência da palavra modelo nesses artigos foi o critério de escolha dos autores. A revisão foi realizada por meio do banco de dados ERIC - Educational Resources Information Center - e durou dez anos (1986-1996). Os autores salientaram que o tema modelos (sugiro colocar o termo "modelos" em destaque - itálico) estaria sendo foco de inúmeras investigações feitas pela comunidade acadêmica internacional que realiza pesquisa na área de educação em ciências.

Quinto \& Ferracioli (2008) procuraram traçar um recorte do desenvolvimento da produção científica sobre modelos e modelagem na década de 1996-2006. Esses autores realizaram uma revisão de artigos publicados em periódicos brasileiros, a saber: Revista Brasileira em Ensino de Física, Caderno Brasileiro de Ensino de Física, Investigações em Ensino de Ciências, Ciência e Educação e Revista Brasileira de Pesquisa em Educação em Ciências. Obtiveram uma seleção de 30 artigos, os quais foram enquadrados em 3 categorias (Referencial Teórico de Johnson-Laird, Ambientes de Modelagem Computacional e Revisão de Literatura).

Dos resultados apontados por Quinto \& Ferracioli (2008), é interessante destacar que a metade das publicações analisadas por eles foi enquadrada na categoria Referencial Teórico de Johnson-Laird. Na categoria Ambiente de Modelagem Computacional destacam a ausência da adoção de um referencial teórico único para o estudo. Em relação à categoria de Revisão de Literatura, os autores observaram que os pesquisadores em educação em ciências recomendam que é preciso tomar cuidado em relação à polissemia da definição de modelos, evitando possíveis desencontros teóricos.

$\mathrm{Na}$ reflexão sobre a atividade científica apresentada por Kneller (1980), os modelos são considerados como sendo partes integrantes das teorias. No entanto, o autor alerta que modelo é "[...] um dos termos mais sobrecarregados de conotaçôes de toda a ciência." (p. 139). Diante disso, ele sugere uma classificação dos modelos em: modelo representacional, modelo teórico e modelo imaginário. 
O modelo representacional é caracterizado como sendo uma representação tridimensional de algo. Como exemplo, é possível citar os modelos do sistema solar, utilizados normalmente em museus ou escolas; maquetes que representam obras de engenharia, como a construção de prédio, represa, carro, avião; maquetes que retratam cenários, pessoas, entre outros.

O modelo teórico é composto por um conjunto de pressupostos sobre um objeto ou sistema, e atribui a estes uma estrutura ou mecanismo interno. Kneller considera o modelo teórico o mais importante utilizado na ciência. Alguns exemplos são: modelo de bola de bilhar; modelo corpuscular da luz; modelo helicoidal da molécula de DNA. Outra característica importante desse tipo de modelo é a possibilidade de ele poder ser descrito matematicamente.

O modelo imaginário é definido como um conjunto de suposições apresentadas para descrever como seria um objeto ou sistema se fossem satisfeitas certas condições. Esse modelo poderá melhorar a nossa compreensão sobre os pressupostos que o constituem e, com isso, podemos dar a ele certas aplicações. O modelo mecânico do campo elétrico, apresentado por Maxwell, é um exemplo típico de modelo imaginário.

Outros autores também apresentam uma caracterização para o termo modelo. Johnson-Laird (1983) considera que modelos são representações mentais analógicas, em certa medida abstraídas de conceitos ou eventos que são espacial e temporalmente análogos às impressões sensoriais. Para Gilbert \& Boulter (1998) os modelos são construídos a partir de representações de uma ideia, um objeto, um evento, ou um sistema. Segundo eles, é possível distinguir quatro tipos de modelos:

- modelo mental - representação pessoal e privada de um alvo;

- modelo expresso - uma versão do modelo mental que é retratada pela pessoa mediante a realização de uma ação, da fala ou da escrita;

- modelo consensual - um modelo expresso e que foi submetido à avaliação de um grupo social, por exemplo a comunidade científica, e sobre o qual se forma um consenso e se atribui mérito;

- modelo pedagógico - um modelo construído e utilizado para auxiliar na compreensão de um modelo consensual.

Para Martinand (1986) há um conjunto de características que podem ser atribuídas aos modelos, considerando-os hipotéticos, modificáveis e pertinentes a determinados problemas inerentes a certos contextos. Já Bunge (1974) ressalta a importância dos modelos para estabelecer uma relação entre o teórico e o real. Esse valor atribuído aos modelos fez com que Bunge tenha se tornado referência de várias investigações realizadas em aulas de ciências, particularmente naquelas focadas na modelização (PIETROCOLA, 1999; PINHEIRO; PIETROCOLA \& ALVES FILHO, 2001; PINHEIRO, 2003; CUPANI \& PIETROCOLA, 2002; WESTPHAL \& PINHEIRO, 2004; MACHADO \& VIEIRA, 2008; entre outros). Diante disso, a modelização é entendida como "... um processo que consiste na elaboração de uma construção mental que pode ser manipulada e que procura compreender um real complexo" (PINHEIRO; PIETROCOLA \& ALVES FILHO, 2001, p. 39). Assume-se, então, 
que para fins de construção do conhecimento escolar, o que é importante não é a simples apresentação do modelo consensual ao estudante, mas o processo de construção de modelos, ou seja, a vivência do processo de modelização, para se apropriar de um modelo já construído.

Vale lembrar que uma das atribuições dos professores é a apresentação de explicações a seus estudantes e, nesse aspecto, Gilbert et al. (2000) afirmam que “... a seleção de um modelo relevante e o oferecimento de uma explicação apropriada são centrais para manutenção de um envolvimento ativo na aprendizagem de ciência” (p. 208). Na mesma linha de argumentação, Custódio (2007) declara que as explicações fazem uso extensivo de modelos. Isso fez com que, nos últimos anos, cada vez mais, fossem realizadas a preparação e a implementação de atividades didáticas de modelização nas aulas de Ciências e Matemática.

As atividades didáticas de modelização já possuem uma maior tradição nas aulas de Matemática e de Física, visando, em sua maioria, à construção de modelos teóricos (pautados em descrições matemáticas). Nas aulas de Química e Biologia também foram realizados alguns estudos sobre o uso de atividades de modelização. Nelas, as atividades acontecem em menor número e possuem características distintas, pautadas na construção de modelos representacionais.

Greca \& Santos (2005) aprofundaram essa reflexão sobre as diferenças entre os tipos de modelização realizados nas distintas áreas do conhecimento. Eles afirmam, inicialmente, que na revisão literária que realizaram puderam constatar que o ensino centrado na modelização é considerado como uma das estratégias didáticas mais efetivas para a melhoria da compreensão dos conceitos científicos. Porém, por meio de uma comparação entre a Física e a Química, alertam para a necessidade de se considerar as diferenças entre as especificidades das ciências. Dessa reflexão, evidencia-se que enquanto na Física a modelização se faz por meio de análises fenomenológicas e descrições matemáticas, na Química é muito mais evidente a presença de elementos pictóricos.

$\mathrm{Na}$ Biologia, há alguns estudos realizados sobre o uso de atividades didáticas de modelização. Paz et AL (2006) descrevem e analisam uma situação didática em que trabalharam o tema cadeia alimentar via modelização, na $4^{\mathrm{a}}$ série do Ensino Fundamental de uma escola brasileira. Para o desenvolvimento dessa ação de ensinoaprendizagem, os autores utilizaram modelos e representações apresentados em livros didáticos de diferentes séries, inclusive dos níveis médio e superior. Da análise feita, destacam que os modelos devem ser utilizados como recursos aproximativos e não como realidades, auxiliando no processo explicativo e, dessa forma, promovendo uma maior compreensão por parte dos estudantes. Ressaltam, ainda, que o papel do professor é fundamental para promover a interação necessária à aprendizagem via processo de modelização.

Felipe; Gallarreta \& Merino (2005) apresentam uma reflexão sobre a utilização e o desenvolvimento de atividades didáticas em que são construídos modelos descritivos e explicativos, em um contexto de formação inicial de professores de ciências (trabalho desenvolvido na Argentina). A temática focada 
é a segmentação embrionária. Os autores assumem os modelos como sendo o núcleo central do conhecimento científico. Já a modelização no contexto escolar é vista por eles como um dos principais processos para apropriação e utilização do conhecimento científico. Assim, consideram que o trabalho feito permitiu que os estudantes (futuros professores) promovessem uma reelaboração e utilização crítica dos modelos.

Braga et al (2009) descrevem e analisam uma atividade didática de modelização direcionada para o Ensino Médio, abordando a divisão celular. Segundo os autores, os processos de divisão celular são de difícil compreensão por parte dos estudantes, de forma geral, por envolverem altos graus de abstração no processo de conceitualização. Visando superar essa dificuldade, eles elaboraram e desenvolveram uma atividade de modelização (construção de modelos representacionais), fundamentada na teoria da aprendizagem significativa.

Mediante os três artigos citados acima, que fazem uma relfexão sobre o uso da modelização no ensino da Biologia, percebemos que a temática está presente desde o Ensino Fundamental até a formação de professores. No entanto, tendo em vista a natureza dos conhecimentos da Biologia, os modelos constituídos são predominantemente compostos por representações tridimensionais (maquetes) ou por elementos pictóricos. A atividade de modelização que buscamos retratar neste artigo se refere à conceitualização do corpo humano. Para isso, apresentamos, inicialmente, uma breve descrição de como esse tópico é abordado em alguns livros didáticos utilizados no Ensino Médio das escolas brasileiras.

\section{CARACTERIZAC̣ÃO DO ESPAC̣O E METODOLOGIA DE DESENVOLVIMENTO DO TRABALHO}

O trabalho foi desenvolvido por um dos autores deste artigo, professor de Biologia, junto a uma escola técnica do Ensino Médio da cidade de Caxias do Sul, no Rio Grande do Sul. A motivação partiu da constatação da dificuldade dos estudantes da $2^{\mathrm{a}}$ série na compreensão da anatomia humana e na construção dos conceitos trabalhados em sala de aula. Diante disso, conjuntamente, os professores da área de Ciências da Natureza, Matemática e suas Tecnologias desenvolveram uma atividade intitulada Descobrindo o Corpo Humano.

O planejamento e o desenvolvimento dessa atividade também buscaram superar a forma tradicional de apresentação do corpo humano nos livros didáticos (sistemas corpóreos isolados). O corpo humano, quando objeto de ensino, é geralmente apresentado aos pedaços. Nas séries iniciais, ele é dividido em três partes, cabeça, tronco e membros; e, na sequência, é dividido em sistemas, como digestório, respiratório, circulatório, etc. No Ensino Médio, o assunto corpo humano é trabalhado entre os temas células e funções celulares. Além disso, não há uma exclusividade na abordagem do corpo humano, mas são 
tratados os sistemas corpóreos de diferentes seres vivos. E, assim por diante, segue-se fragmentando.

Sendo assim, tendo como base a anatomia humana, os principais objetivos da atividade foram: estabelecer relações entre os conteúdos discutidos; desenvolver conteúdos de forma prática; contextualizar os assuntos estudados para propiciar condições de utilização dos conhecimentos teóricos, trabalhados com os estudantes, em situações práticas; incentivar a atitude científica, a pesquisa e o planejamento.

Essa ideia está de acordo com Trivelato (2005), que sinaliza que nos programas atuais, observa-se uma valorização de abordagens integradoras, as quais buscam incentivar as considerações interdisciplinares no estudo do corpo humano "[...] como um todo integrado, cuja organização e complexidade são, em si mesmas, objetos de conhecimento." (p. 126).

A atividade foi desenvolvida durante todo o ano letivo e estava estruturada em etapas diferenciadas conforme os objetivos. Ao final da execução de todas as etapas, os estudantes finalizaram a construção de modelos representacionais do corpo humano. Para isso, utilizaram materiais alternativos e/ou recicláveis, sugeridos pelos próprios estudantes, assim como textos e figuras explicativas das estruturas anatômicas estudadas, obedecendo aos critérios de similaridade, aparência e consistência. Como o propósito da atividade também era desenvolver a aprendizagem conceitual relativa ao tema corpo humano, os estudantes transitaram por diferentes bibliografias pesquisadas individualmente ou sugeridas pelo professor.

A turma foi dividida em oito grupos, ficando ao encargo de cada grupo se organizar para a pesquisa dos sistemas do corpo humano. Esses sistemas foram previamente selecionados, sendo eles os sistemas de sustentação, integração (nervoso e endócrino), cardiovascular, digestório, urinário, respiratório e genital masculino e feminino.

\section{Etapas de desenvolvimento da atividade}

A primeira etapa teve como propósito a organização dos grupos e a busca e coleta de informações. Na parte que se refere à pesquisa, foi solicitado aos estudantes que buscassem informações sobre a anatomia e fisiologia desses sistemas. Durante esse processo, também foi realizada uma visita ao Laboratório de Anatomia da Universidade de Caxias do Sul (UCS), para que, in loco, pudessem visualizar as estruturas anatômicas que compõem o organismo humano (no que se refere às dimensões, localização e textura em um modelo anatômico natural e tridimensional; não em estruturas planas como ilustrações dos livros textos).

A segunda etapa do projeto consistiu em aplicar esses conhecimentos em situações organizadas pelos professores das diferentes disciplinas. Foi solicitado aos estudantes a escolha de um biotipo masculino e um feminino, feitos em papel pardo, que descrevesse melhor a anatomia humana de acordo com os princípios da simetria espacial. Em suma, essa etapa representou o início da construção do modelo representacional do corpo humano. 
$\mathrm{Na}$ terceira etapa, os estudantes foram orientados para fazer a montagem de um modelo anatômico real, utilizando como base o esboço que fizeram no papel pardo, porém, passando para uma estrutura tridimensional. A primeira parte consistiu na montagem da estrutura externa do corpo do biotipo?, utilizando faixas de gesso ortopédico. A segunda parte do trabalho foi a de completar essa estrutura oca com modelos representacionais dos órgãos, que foram encaixados de forma a mostrar sua integração, da maneira mais próxima à realidade. Os órgãos deveriam ser estruturados utilizando material alternativo e reciclável que representasse a textura mais aproximada dos originais, dentro das medidas realizadas durante a pesquisa.

Ao final dessas atividades os estudantes apresentaram aos professores o modelo anatômico montado, relatando todas as etapas, ou seja, como foram executados, elaborados e montados os diversos sistemas.

\section{RESULTADOS E ANÁLISE}

Na primeira etapa do trabalho, que consistiu em pesquisar dados relativos à anatomia e à fisiologia do corpo humano, os estudantes não tiveram dificuldades em encontrar informações referentes aos sistemas corpóreos, mas em aplicar os conceitos necessários para a confecção do modelo. Essa dificuldade ocorreu devido à fragmentação dos sistemas e à não integração e ausência de interdependências com os demais.

Pode-se perceber que o estudo do corpo, por sua dimensão e complexidade, é feito apenas por meio da divisão em pedaços, sendo fragmentado e esquartejado, visto assim na educação e pela própria ciência. Dessa maneira, o estudo dos diversos sistemas do corpo ocorre de forma mecânica e reducionista, o que pode acarretar em uma desarticulação de conceitos e ideias por parte dos estudantes, decorrente da falta de uma continuidade por meio da qual esses sistemas poderiam se integrar em um mesmo corpo (TRIVELATO, 2005). Dessa forma, foi necessário realizar uma aula no laboratório de anatomia, buscando enfatizar as conexões existentes com um ou mais sistemas corpóreos.

Durante a aula no laboratório de anatomia, observamos a ansiedade e o medo dos estudantes em se deparar com uma peça anatômica (cadáver). Primeiramente, foram expostos os órgãos separados do corpo, que estavam fixados em formol, acondicionados em potes de vidro. Em seguida, os estudantes foram levados à sala de dissecação para que pudessem examinar a peça anatômica inteira. Os estudantes observavam a disposição, o formato, a textura e a cor dos órgãos, e buscavam comparar com as imagens de livros. A maioria deles questionava a cor e o tamanho dos órgãos, relatando que as imagens dos livros não apareciam da forma como estava no corpo real. Além disso, demonstravam curiosidade e perguntavam onde estavam órgãos e sistemas que não apareciam, como por exemplo o sistema excretor o qual ficava na porção dorsal, por trás dos intestinos, o que as imagens dos livros não apresentam. 
Durante a atividade no laboratório, o professor buscou sanar as dúvidas dos estudantes, principalmente no aspecto de integração de um sistema a outro, conforme o questionamento dos grupos.

$\mathrm{Na}$ segunda etapa, usando como base a própria estrutura corpórea dos biotipos selecionados, os grupos iniciaram o desenvolvimento de esboços dos sistemas corpóreos pesquisados na atividade anterior, respeitando a localização correta, formato e as escalas dos órgãos dos diferentes sistemas.

Em seguida, os estudantes realizaram mensurações do biotipo, organizaram uma tabela de medidas, assinalaram as medidas que se aproximavam mais umas das outras e calcularam a área da pele. Depois disso, iniciaram o contorno do biotipo em um papel pardo, sendo que um estudante foi selecionado e deitou sobre o papel para que os colegas passassem um lápis em seu contorno (Fig. 1).

Figura 1: Contorno do biotipo selecionado.

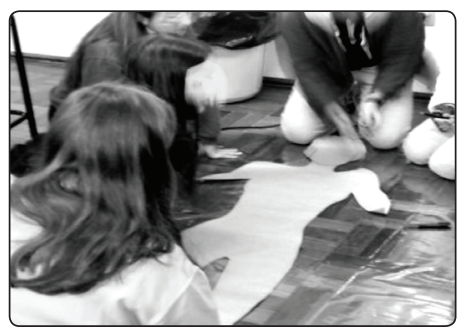

Na sequência, os estudantes representaram, nas regiões torácica e abdominal, os órgãos que compõem o organismo, tendo como referência sua localização nos atlas de anatomia, para que pudessem chegar o mais próximo à realidade, relacionando as imagens dos livros com o seu próprio corpo (Fig. 2 e 3).

Figura 2: Esboço do sistema de sustentação.

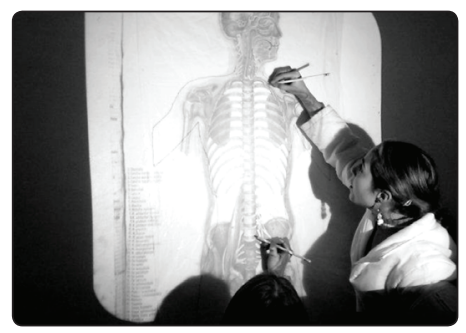

Figura 3: Grupos trabalhando no biotipo.

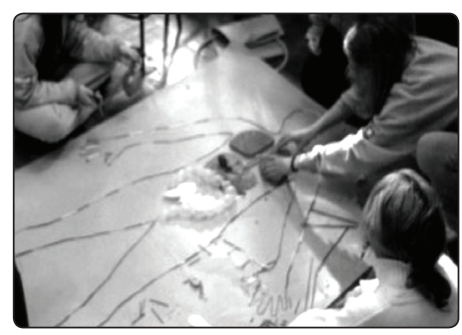

A terceira etapa consistiu na montagem da estrutura externa do corpo do biotipo. A técnica utilizada foi a de engessamento (Fig. 4), pela qual o biotipo foi engessado da altura do pescoço até a um palmo acima da altura do joelho. Depois de seca, a estrutura foi cortada lateralmente, separando a porção ventral da dorsal. 
Figura 4: Técnica de engessamento.

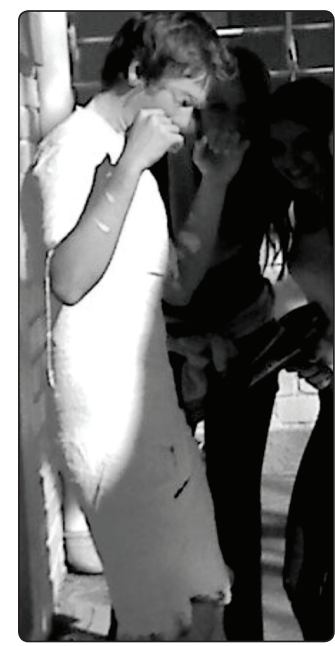

Essa manta de gesso do biotipo serviu de modelo da pele e como base para que os grupos pudessem montar os sistemas dentro da cavidade torácica e abdominal. Como havia um biotipo masculino e um feminino por turma, os estudantes tinham que se organizar para montar os sistemas da mesma forma em que estão estruturados no nosso organismo.

De início, encontraram dificuldades em saber por qual sistema iriam começar a montagem, e, após algumas discussões, optaram pela coluna vertebral, montada com tampinhas de garrafas e de potes (para representar as vértebras), restos de lâminas de EVA (emborachado denominado Etileno Acetato de Vinila) (para representar os discos intervertebrais) e um fio de alumínio flexível (que passaram por dentro dessa estrutura para representar os nervos). Para os demais ossos, foi utilizado papel para moldar a estrutura óssea que compunha a região torácica e abdominal. Esses moldes foram finalizados com o resto das faixas ortopédicas utilizadas no engessamento do biotipo. As costelas foram fixadas junto ao gesso da estrutura da pele.

Para iniciar a estruturação dos sistemas no biotipo, os estudantes resolveram posicionar primeiramente o diafragma, o que orientaria a divisão das porções abdominais e torácica. O diafragma foi representado por um "balão surpresa" de festa de aniversário e foram colados barbantes que serviram de representação dos nervos periféricos responsáveis pelo processo de ventilação pulmonar.

$\mathrm{Na}$ região torácica, os grupos montaram o sistema respiratório. Para isso, utilizaram um tubo anelado, usado em fiação telefônica, como representação da traqueia, pois assim estariam representando os anéis cartilaginosos. Esse mesmo material serviu para caracterizar os brônquios. O pulmão foi representado por esponja devidamente pintada, com destaque para suas respectivas divisões. Já os bronquíolos foram retratados pelo revestimento dos fios de telefones. 
O grupo responsável pelo sistema circulatório dispôs o coração entre os pulmões, com a representação das principais artérias e veias. O coração foi estruturado por uma esponja vegetal para representar as fibras e as cavidades cardíacas e estas foram envoltas por massa de modelar. Ele foi confeccionado inteiro e estava fechado, mas possuía um corte sagital mediante o qual poderia ser aberto para observação das cavidades cardíacas. Para a representação dos vasos sanguíneos, foram utilizadas mangueiras de diferentes diâmetros. Houve preocupação dos dois grupos em fazer a integração desses dois sistemas, pois teriam que explicar como ocorre a hematose. Dessa forma, resolveram utilizar revestimento dos fios de telefones, pintá-los de azul e vermelho e conectar essa representação de capilares ao final dos bronquíolos, onde ficam os alvéolos pulmonares.

Outra dificuldade encontrada pelos estudantes nessa montagem foi a localização do esôfago. Inicialmente eles o puseram sobre a traqueia, porém não estavam certos sobre essa posição e, após algumas discussões e análises de seu próprio corpo, o posicionaram atrás da traqueia. Para a representação do esôfago foi utilizado um cano de PVC e na parte interna foi colocada espuma para representar os músculos que fazem os movimentos peristálticos.

$\mathrm{Na}$ porção abdominal, os estudantes começaram pelo sistema excretor, visto que esse se encontra na porção dorsal do nosso corpo. Os rins foram colocados logo abaixo do diafragma, estruturados com papel machê e envoltos por massa de modelar. Em sua porção superior foram colocadas as glândulas suprarrenais, representadas com esponja. Para caracterizar os ureteres e a uretra, foram utilizados os revestimentos dos fios de telefone. Já a bexiga foi representada por um balão. Nessa montagem houve a preocupação dos estudantes em interligar o sistema urinário com o circulatório, para que pudessem explicar como ocorre o processo de filtração renal. As principais artérias e veias renais foram representadas por canudinhos e as caracterizações dos capilares também foram colocadas nas glândulas suprarrenais. A maior discussão sobre o sistema excretor ocorreu devido às várias informações diferenciadas sobre o volume da bexiga. Dessa forma, o grupo resolveu utilizar o balão para representar a capacidade de dilatação que a bexiga possui, devido a sua estrutura muscular, que varia conforme a filtração renal de cada pessoa.

Depois de organizado o sistema excretor, o grupo do sistema digestório iniciou a colocação dos órgãos. O estômago foi representado externamente por um balão e internamente com retalhos de espuma para que pudesse conferir maleabilidade e demonstrar a continuidade do movimento peristáltico iniciado no esôfago. Para o intestino delgado foram utilizados preservativos masculinos e "balões canudos". $\mathrm{Na}$ confecção do intestino grosso foram utilizados retalhos de esponja envoltos em tecidos que foram costurados em forma de tubo. Em todo o tubo digestório foram colados barbantes para representar os nervos periféricos e os revestimentos de fio de telefone pintados caracterizando os capilares sanguíneos. O fígado foi representado com um balão e preenchido com serragem e farinha, que serviu para moldar a forma anatômica, além de aproximar de sua massa. A vesícula biliar foi representada por uma "bexiguinha de água" verde, sendo conectado o duto ao fígado e ao pâncreas. O pâncreas foi 
anexado na porção mediana do duodeno e foi representado por esponja vegetal. Nele, também foram representados os capilares sanguíneos, devido a sua função endócrina.

Ao término da montagem dos modelos em sala de aula (Fig. 5), os estudantes apresentaram o trabalho. Para isso, foram em busca de informações, pesquisaram sobre métodos alternativos e materiais que poderiam representar cada estrutura. Esses materiais foram selecionados em virtude da semelhança com as estruturas corporais (cor, textura, massa, volume), conforme a descrição feita anteriormente, o que viabilizou a aquisição de conceitos relacionados ao volume, tamanho, localização, relações e tridimensionalidade dos órgãos e sistemas, bem como também despertou a preocupação em se integrar a fisiologia dos órgãos, considerando sua localização e levando em conta suas relações de vizinhança e espaço.

Figura 5: Modelo final montado.

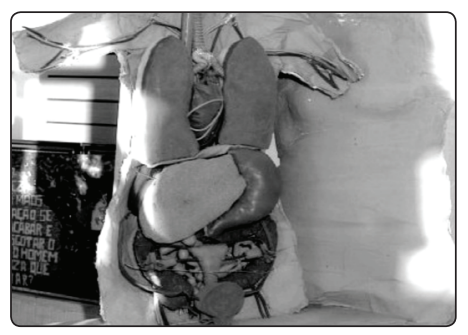

O processo de modelização possibilitou aos estudantes o desenvolvimento de conceitos próximos da realidade e a integração anatomo-fisiológica, propiciando a compreensão de fenômenos como a respiração, a circulação, a reprodução e a hematose. Durante toda a execução do trabalho o que chamou atenção foi a demonstração constante de curiosidade e entusiasmo por parte dos estudantes (Fig. 6).

Figura 6: Sala de aula no momento da montagem do modelo do corpo.

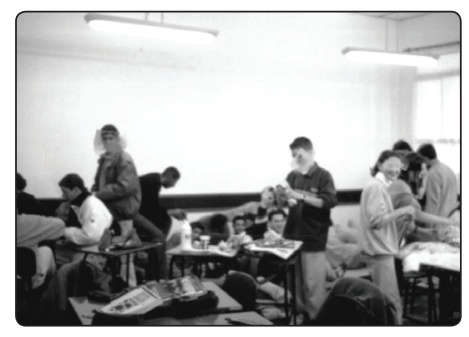

Ressaltamos, ainda, que o envolvimento dos estudantes ao longo de todo o processo proporcionou-lhes uma compreensão abrangente sobre o que é e como está estruturado o corpo humano. Essa compreensão foi sendo construída gradativamente, mediante estudos teóricos, pesquisas, visitas e aulas em laboratório, e culminou com a finalização da construção de um modelo representacional do corpo humano. 


\section{ALGUMAS CONSIDERAÇÕES}

A atividade de modelização para a conceitualização do corpo humano possibilitou a superação de algumas dificuldades enfrentadas pelos estudantes quando esse tema é abordado somente por meio dos livros didáticos. Dentre essas dificuldades, destacamos como mais problemáticas a planificação, o reducionismo e a descontextualização (quando cada sistema é estudado isoladamente), além da desproporcionalidade das estruturas representadas nas figuras em comparação com as reais. Os estudantes, ao longo do processo de modelização, tiveram a oportunidade de se defrontar com essas dificuldades que puderam ser superadas mediante a discussão realizada entre eles e com os professores.

A fragmentação também é um dos problemas que apontamos anteriormente, no entanto, é um desafio superá-lo em virtude da complexidade característica do estudo do corpo humano, o que exige um conhecimento tanto de cada sistema em particular, quanto da totalidade e integração que são fundamentais a ele. Em virtude disso, a turma foi organizada em grupos que se dedicaram inicialmente ao estudo e modelização de um sistema particular para, posteriormente (e em grande grupo), finalizarem a construção do modelo representacional (tridimensional) do corpo humano completo. A construção desse modelo permitiu aos estudantes uma melhor percepção e compreensão da integralização dos sistemas corpóreos, possibilitando uma visualização de totalidade.

As diferentes atividades desenvolvidas durante o processo de modelização propiciaram uma clara relação entre o teórico e o real. Esse aspecto vai ao encontro da leitura que Bunge (1974) faz quando trata da importância dos modelos na ciência, ao discutir teoria e realidade. Essa relação é também significativa no contexto educacional, pois permite que os estudantes utilizem, em outras situações, os conhecimentos produzidos na escola. Isso se maximiza quando a atividade é organizada e mediada pelo professor de forma a permitir uma participação ativa do estudante e um espaço para reflexão e tomada de decisão.

É importante ressaltar que a tradição da modelização no ensino de ciências está fortemente pautada na construção de modelos teóricos (matematizáveis e sintetizados em expressões matemáticas), no entanto, a construção de modelos representacionais assume uma importância significativa para o desenvolvimento da aprendizagem em disciplinas como a Biologia. Dessa maneira, acreditamos que os modelos representacionais são tão significativos para o ensino da Biologia e da Química como os modelos teóricos são para as disciplinas de Física e Matemática. Diante disso, concordamos com Greca \& Santos (2005) quando essas autoras alertam para a necessidade de se considerar as diferenças entre as especificidades das ciências ao trabalhar seus conceitos via modelização.

A modelização no ensino de Biologia se apresenta como uma possibilidade efetiva para o processo de ensino-apredizagem. Porém, julgamos que é importante a ocorrência dessa discussão em diferentes níveis educacionais, sejam eles voltados à educação básica (Ensino Fundamental e Médio) ou à profissional 
(formação inicial e continuada de professores). Nesse sentido, acreditamos que o processo de modelização se configura em um campo propício para futuras pesquisas na educação científica, sobretudo na área de ensino de Biologia.

\section{REFERÊNCIAS}

BRAGA, C. M. D. da S. et al. O uso de modelos no ensino da divisão celular na perspectiva da aprendizagem significativa. In: ENCONTRO NACIONAL DE PESQUISA EM EDUCAÇÃO EM CIÊNCIAS, 7., 2009, Florianópolis, SC. Atas... Florianópolis: Associação Brasileira de Pesquisa em Ensino de Ciências, 2009.

BUNGE, M. Teoria e realidade. São Paulo: Perspectiva, 1974.

CICILLINI, G. A. Ensino de Biologia: o livro didático e a prática pedagógica dos professores no Ensino Médio. Ensino em Revista, local da publicação? v. 6, n. 1, p. 29-37. 1998.

CUPANI, A. \& PIETROCOLA, M. A relevância da epistemologia de Mario Bunge para o ensino de ciências. Caderno Brasileiro de Ensino de Física, v. 19, n. especial, p. 100-125. 2002.

CUSTÓDIO, J. F. Explicando explicações na educação científica: domínio cognitivo, status afetivo e sentimento de entendimento. Tese (Doutorado em Educação Científica e Tecnológica) - Programa de pós-graduação em Educação Científica e Tecnológica. Universidade Federal de Santa Catarina, Florianópolis, 2007.

FELIPE, A. E.; GALLARRETA, S. C. \& MERINO, G. La modelización en la enseñanza de la biología del desarrollo. Revista Electrónica de Enseñanz̧a de las Ciencias, v. 4, n. 3, 2005. Disponível em: <http://www.saum.uvigo.es/reec>. Acesso em: jan. 2011.

FRACALANZA, H. O que sabemos sobre os livros didáticos para o ensino de Ciências no Brasil. 1993. Tese (Doutorado em Educação) - Faculdade de Educação, Universidade Estadual de Campinas, Campinas, 1993.

Gilbert, J. K.; Boulter,C.J. \& Rutherford, M. Explanations with models in science education. In: GILBERT, J. K e BOULTER, C. J. (eds). Developing models in science education. Dordrecht: Kluwer, 2000, p. 193-208.

GILBERT, J. K e BOULTER, C. J. Aprendendo ciências através de modelos e modelagem. In: COLINVAUX, D. (org). Modelos e educação em ciências. Rio de Janeiro: Ravil, p. 12-34, 1998.

GRECA, I. M. \& SANTOS, F. M. T. Dificuldades da generalização das estratégias de modelação em ciências: o caso da física e da química. Investigações em Ensino de Ciências, v.10. n.1, p. 31-46. 2005.

JONHSON-LAIRD, P. Mental Models. Cambridge: Cambridge University Press, 1983.

KNELLER, G. F. A ciência como atividade humana. $2^{\mathrm{a}}$ ed. Rio de Janeiro: Zahar, 1980.

KRAPAS, S., et al. Modelos: uma análise de sentidos na literatura de pesquisa em Ensino de Ciências. Investigações em Ensino de Ciências, v. 2, n. 3, p.185-205. 1997.

KRASILCHICK, M. Prática de ensino de Biologia. São Paulo: Editora da USP, 2008.

MACHADO, J. \& VIEIRA K. S. Modelização no ensino de física: contribuições em uma perspectiva bungeana. In: ENCONTRO DE PESQUISA EM ENSINO DE FÍSICA, 11., 2008. Curitiba, Atas... Curitiba: SBF, 2008.

MARTINAND, J. L. Ensenãnza y aprendizage de la modelizacion. Enseñan ąa de las Ciencias, Barcelona, v. 4, n.1, p. 45-50. 1986.

PAZ, A. M. da; et al. Modelos e modelizações no ensino: um estudo da cadeia alimentar. Ensaio, v. 8, n.2, p. 133-146. 2006.

PIETROCOLA, M. Construção e Realidade: o realismo científico de Mário Bunge e o ensino de ciências através de modelos. Investigações em Ensino de Ciências. Porto Alegre. IFUFRGS, v. 4, n. 3, p. 213-227. 1999.

PINHEIRO, T. de F.; PIETROCOLA, M. \& ALVES FILHO, J. Modelização de variáveis: uma maneira de caracterizar o papel estruturador da Matemática no conhecimento científico. In: PIETROCOLA, Maurício (Org.). Ensino de Física: conteúdo, metodologia e epistemologia numa concepção integradora. Florianópolis: UFSC, 2001. p. 33-52. 
PINHEIRO, T. F. Sentimento de realidade, afetividade e cognição no ensino de ciências. 2003. Tese (Doutorado em Educação Científica e Tecnológica) - Programa de pós-graduação em Educação Científica e Tecnológica, Universidade Federal de Santa Catarina, Florianópolis, 2003.

QUINTO, T. \& FERRACIOLI, L. Modelos e modelagem no contexto do ensino de ciências no Brasil: uma revisão de literatura de 1996-2006. Revista Didática Sistêmica, v. 8, p. 80-100. 2008.

TRIVELATO, S. L. F. Que corpo/ser humano habita nossas escolas? In: MARANDINO, M. et al. Ensino de Biologia: conhecimentos e valores em disputa. Niterói, RJ: Eduff, 2005, p.121-130.

WESTPHAL, M. \& PINHEIRO, T. C. A epistemologia de Mario Bunge e sua contribuição para o Ensino de Ciências. Ciência \& Educação, Bauru, SP, v.10. n.3, p. 585-596. 2004.

Data de Recebimento: 18/06/2011

Data de Aprovação: 13/11/2011

Data da Versão Final: 20/12/2011 